\title{
Extracorporeal membrane oxygenation as a direct bridge to heart transplantation in adults
}

\author{
Shinichi Fukuhara, MD, Koji Takeda, MD, PhD, Paul A. Kurlansky, MD, Yoshifumi Naka, MD, PhD, and \\ Hiroo Takayama, MD, $\mathrm{PhD}$
}

\section{ABSTRACT}

Objectives: Venoarterial extracorporeal membrane oxygenation (ECMO) use as a bridge to transplant is extremely infrequent in adults. We investigated patient outcomes of the use of ECMO as bridge to transplant.

Methods: United Network of Organ Sharing provided de-identified patient-level data. Between 2003 and 2016, 25,168 adult recipients were identified. Of these, $107(0.4 \%)$ were bridged with ECMO and $6148(24.4 \%)$ were bridged with a continuous-flow left ventricular assist device.

Results: Patients in ECMO group were younger, more likely to have severely disabled functional status, shorter waitlist time, and were more frequently mechanically ventilated than were patients in the continuous-flow left ventricular assist device group. Kaplan-Meier analysis demonstrated estimated posttransplant survival of $73.1 \%$ versus $93.1 \%$ at 90 days $(P<.001)$ and $67.4 \%$ versus $82.4 \%$ at 3 years $(P<.001)$ in ECMO and continuous-flow left ventricular assist device groups, respectively. Analysis of a propensity-matched cohort still demonstrated a lower survival in ECMO group at 90 days $(74.8 \%$ vs $88.8 \% ; P=.025)$ and 3 years $(69.3 \%$ vs $82.2 \% ; P=.054)$. Among the ECMO patients, multivariable logistic and Cox regression analyses showed model for end-stage liver disease excluding international normalized ratio (MELD-XI) score to be the sole contributor to both 90-day (odds ratio, 1.94; 95\% confidence interval, 1.00$3.76 ; P=.050$ ) and 3-year mortality (hazard ratio, $1.47 ; 95 \%$ confidence interval, 1.16-1.88; $P=.002)$. ECMO-supported patients with a high MELD-XI score $(>17)$ were associated with poor posttransplant survival compared with those with a low MELD-XI score $(<13)$ (90 day, 54.4\% vs $85.0 \%[P<.001]$ and 3 year, $49.5 \%$ vs $73.5 \%[P<.001])$.

Conclusions: Bridge to transplant with ECMO was associated with increased early/mid-term mortality, especially in patients with a high MELD-XI score who demonstrated $>50 \%$ 3-year mortality. These findings may help to inform future organ allocation policies. (J Thorac Cardiovasc Surg 2018;155:1607-18)

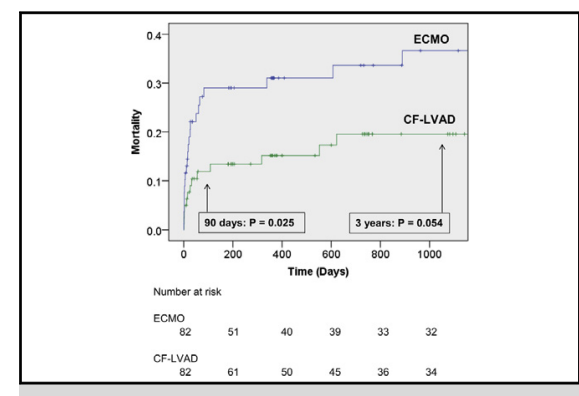

Kaplan-Meier curves for posttransplant mortality up to 3 years after propensity matching.

\section{Central Message}

Patients bridged to transplant with extracorporeal membrane oxygenation were associated with increased early/midterm mortality compared with those with continuous-flow left ventricular assist device.

\section{Perspective}

Extracorporeal membrane oxygenation use as a bridge-to-transplant is extremely infrequent in adults. Patients directly bridged to transplant with extracorporeal membrane oxygenation were associated with increased early/midterm mortality compared with those supported with a continuous-flow left ventricular assist device.

See Editorial Commentary page 1619.
Heart transplantation today remains the gold standard for end-stage heart failure refractory to medical management. Due to a nationwide scarcity in donor organs, there has

\footnotetext{
From the Division of Cardiac, Thoracic, and Vascular Surgery, Columbia University Medical Center, New York, NY

Read at the 97th Annual Meeting of The American Association for Thoracic Surgery, Boston, Massachusetts, April 29-May 3, 2017.

Received for publication May 1, 2017; revisions received Oct 1, 2017; accepted for publication Oct 30, 2017; available ahead of print Jan 17, 2018.

Address for reprints: Hiroo Takayama, MD, PhD, Division of Cardiac, Thoracic, and Vascular Surgery, Columbia University Medical Center, 177 Fort Washington Ave, New York, NY 10032 (E-mail: ht2225@cumc.columbia.edu). $0022-5223 / \$ 36.00$

Copyright (c) 2017 by The American Association for Thoracic Surgery https://doi.org/10.1016/j.jtcvs.2017.10.152
}

been rapid growth in the field of mechanical circulatory support (MCS). Specifically, the bridge-to-transplant (BTT) strategy with continuous-flow ventricular assist devices (CF-LVADs) has played a major role in providing temporary support for adult patients with end-stage heart

Scanning this QR code will
take you to a supplemental
video, tables, and figures. To
view the AATS Annual
Meeting Webcast, see the
URL next to the webcast
thumbnail.




$\begin{aligned} & \text { Abbreviations and Acronyms } \\ & \text { BTT = } \text { bridge to transplant } \\ & \text { CF-LVAD = } \text { continuous-flow left ventricular assist } \\ & \text { device } \\ & \text { ECMO }= \text { venoarterial extracorporeal membrane } \\ & \text { oxygenation } \\ & \text { KPS }= \text { Karnofsky performance score } \\ & \text { MCS = } \text { mechanical circulatory support } \\ & \text { MELD-XI = } \text { model for end-stage liver disease } \\ & \text { excluding international normalized } \\ & \text { ratio } \\ &= \text { Organ Procurement and } \\ & \text { OPTN } \text { Transplantation Network } \\ & \text { UNOS = } \text { United Network for Organ Sharing }\end{aligned}$

failure. ${ }^{1}$ Additionally, venoarterial extracorporeal membrane oxygenation (ECMO) use as a rescue therapy in the setting of acute cardiac failure has also been increasing in recent years, ${ }^{2,3}$ whereas use of ECMO as a direct bridge to transplantation in adult populations is extremely infrequent worldwide, particularly in the United States. ${ }^{4}$

Each adult heart transplant candidate at time of registration is assigned a status that reflects his or her medical urgency for transplant. ${ }^{5}$ The advent and increasing clinical use of CF-LVADs has led to a paradigm shift in the medical practice of the heart transplant community. As a consequence, the following major deficits with the current allocation systems have been identified ${ }^{5}$ : there are too many status $1 \mathrm{~A}$ candidates, allocation rules are not aligned with prognosis, certain candidate groups are not well served by the current system and must often request exceptions, and significant regional differences in waiting times and status disparities. With the steady growth in the number of transplant candidates, the current system is in need of change for the goals of reducing waitlist mortality and expanding access to donor hearts for the most critically ill patients. ${ }^{5}$ According to the recent Organ Procurement and Transplantation Network/United Network for Organ Sharing (OPTN/ UNOS) proposal, among the changes in the adult heart allocation system includes candidates who are supported with ECMO to be in the highest priority (status 1) because of their high waiting list mortality rates, and because the number of candidates supported by ECMO before transplant is relatively low. ${ }^{5}$ Although the majority of the proposed changes undoubtedly represent improvements to the current system, there are major concerns, 1 of which is a potential decline in posttransplant survival with the proposed allocation system.

In view of the current ongoing debates regarding the new organ allocation policy and scarcity of studies regarding
ECMO-supported patients who directly undergo BTT, we sought to investigate the posttransplant outcomes among ECMO-supported adult patients to see whether this BTT with ECMO pathway is a viable option by comparing the outcomes of these patients with those of patients supported with CF-LVAD.

\section{METHODS}

\section{Data Collection/Study Population}

A retrospective review of de-identified data from the UNOS Thoracic Registry was performed and identified a total of 25,168 heart transplant recipients aged $\geq 18$ years between January 2003 and March 2016. Of these, $107(0.4 \%)$ patients were bridged with ECMO directly to transplant and $6148(24.4 \%)$ were bridged with CF-LVAD. Patients who underwent retransplantation for graft failure or multiorgan transplant were excluded from the analysis. This study period was chosen in accordance with the beginning of CF-LVAD use. The types of CF-LVADs implanted comprise HeartMate II (Thoratec, Pleasanton, Calif) $(n=4784 ; 77.8 \%)$, HeartWare HVAD (HeartWare International Inc, Framingham, Mass) $(\mathrm{n}=1134$; $18.4 \%$ ), Ventrassist (Ventracor Ltd, Chatswood, New South Wales, Australia) $(\mathrm{n}=101 ; 1.6 \%)$, Jarvik 2000 (Jarvik Heart, Inc, New York, NY) $(\mathrm{n}=96 ; 1.6 \%)$, DuraHeart (TerumoHeart, Ann Arbor, Mich) $(\mathrm{n}=28 ; 0.5 \%$ ), and DeBakey VAD (MicroMed Technology, Inc, Houston, Tex $(n=5 ; 0.1 \%)$. Follow-up ended on June 17, 2016. Posttransplant survival in the present study was defined as absence of death as a result of any cause. UNOS dataset uses Karnofsky performance score ${ }^{6}$ (KPS) to determine the functional status of a recipient. In brief, KPS increases by 10 points from 0 to 100 as the level of independence improves and the symptoms of disease resolve. Functional status in each patient was categorized corresponding to a KPS of 80 to 100 (no assistance), 50 to 70 (some assistance), and 10 to 40 (total assistance). Model for end-stage liver disease excluding international normalized ratio (MELD-XI) score, ${ }^{7}$ a modification to the existing model for end-stage liver disease score, was calculated in each patient. The Columbia University Institutional Review Board approved all aspects of this study and waived informed consent because the database is de-identified and publicly available.

\section{Statistical Analysis}

Continuous variables are expressed as mean \pm 1 standard deviation. Categorical variables are presented as proportions and absolute numbers. Differences between groups were measured using the $\chi^{2}$ or Fisher exact test for categorical and Student $t$ test or the Mann-Whitney $U$ test for continuous variables, as appropriate. Actuarial survival estimates with 95\% confidence intervals (CIs) were assessed according to the method of Kaplan and Meier using time zero as the date of heart transplantation. The equality of survival distribution was tested with the log-rank algorithm. Corresponding $95 \%$ CIs in each time point for Kaplan-Meier curve are shown in Tables E1 to E6. Missing variables were imputed using a multiple imputation technique. Data were assumed to be missing at random from a normal distribution because normal imputations were considered robust even against violations of normality given the large sample size. ${ }^{8}$ Each missing data was imputed 10 times resulting in 10 imputed data sets. All subsequent analyses were performed for each imputed dataset separately and combined to produce a final single set of parameter estimates. Lists of variables with frequency of missing data included in the multiple imputation before the propensity-score matching and the multivariable analyses are shown in Tables E7 to E9. To control for measured potential confounders in the dataset, a propensity score was generated for each patient from a multivariable logistic regression model based on the following clinically relevant variables in the dataset: recipient age, status $1 \mathrm{~A}$, dialysis, MELD-XI score, mechanical ventilator support, intra-aortic balloon pump, inotropic support, functional status, 
TABLE 1. Baseline recipient characteristics

\begin{tabular}{|c|c|c|c|}
\hline Characteristic & $\begin{array}{c}\text { ECMO } \\
(n=107)\end{array}$ & $\begin{array}{l}\text { CF-LVAD } \\
(n=6148)\end{array}$ & $\begin{array}{c}P \\
\text { value }\end{array}$ \\
\hline Age & $44.3 \pm 15.2 *$ & $53.2 \pm 12.2$ & $<.001 *$ \\
\hline Total days on waiting list & $123 \pm 425^{*}$ & $305 \pm 369 *$ & $<.001 *$ \\
\hline ECMO at listing & $40(37.4)^{*}$ & $33(0.5)^{*}$ & $<.001 *$ \\
\hline Female gender & $34(31.8)^{*}$ & $1177(19.1)^{*}$ & $.001 *$ \\
\hline Body mass index & $25.6 \pm 5.1 *$ & $28.3 \pm 5.0^{*}$ & $<.001 *$ \\
\hline $\begin{array}{l}\text { Heart failure etiology } \\
\text { Dilated cardiomyopathy } \\
\text { Ischemic } \\
\text { Congenital } \\
\text { Others }\end{array}$ & $\begin{array}{l}43(40.2)^{*} \\
32(31.8)^{*} \\
11(10.3)^{*} \\
19(17.8)^{*}\end{array}$ & $\begin{array}{c}3309(53.8)^{*} \\
2523(41.0)^{*} \\
36(0.6)^{*} \\
280(4.6)^{*}\end{array}$ & $<.001 *$ \\
\hline $\begin{array}{l}\text { Blood type } \\
\text { O } \\
\text { A } \\
\text { B } \\
\text { AB }\end{array}$ & $\begin{array}{c}41(38.3)^{*} \\
50(46.7)^{*} \\
8(7.5)^{*} \\
8(7.5)^{*}\end{array}$ & $\begin{array}{c}2793(45.4)^{*} \\
2307(37.5)^{*} \\
815(13.3)^{*} \\
233(3.8)^{*}\end{array}$ & $.019 *$ \\
\hline MELD-XI $\dagger$ & $16.1 \pm 6.3^{*}$ & $13.2 \pm 4.2^{*}$ & $<.001 *$ \\
\hline $\begin{array}{l}\text { MELD-XI score } \\
\quad<13 \\
13-17 \\
>17\end{array}$ & $\begin{array}{l}35(34.3)^{*} \\
33(32.4)^{*} \\
34(33.3)^{*}\end{array}$ & $\begin{array}{r}3589(58.8)^{*} \\
1696(27.8)^{*} \\
820(13.4)^{*}\end{array}$ & $<.001 *$ \\
\hline Status 1A & $99(92.5)^{*}$ & $4366(71.0)^{*}$ & $<.001 *$ \\
\hline $\begin{array}{l}\text { Functional status } \\
\text { Total assistance }\end{array}$ & $83(88.3)^{*}$ & $1890(32.1)^{*}$ & $<.001 *$ \\
\hline $\begin{array}{l}\text { Panel reactive antibody } \\
\text { Class I } \\
\text { Class II }\end{array}$ & $\begin{array}{l}9.4 \pm 23.1 \\
8.8 \pm 23.5\end{array}$ & $\begin{array}{l}8.3 \pm 20.2 \\
5.1 \pm 15.8\end{array}$ & $\begin{array}{l}.65 \\
.17\end{array}$ \\
\hline Black race & $17(15.9)$ & $1426(23.2)$ & .075 \\
\hline Diabetes & $16(15.1)^{*}$ & $1879(30.6)^{*}$ & $.001 *$ \\
\hline Dialysis & $7(6.7)^{*}$ & $182(3.0)^{*}$ & $.027 *$ \\
\hline History of CVA & $1(0.9)^{*}$ & $337(5.5)^{*}$ & $<.001 *$ \\
\hline Serum creatinine $(\mathrm{mg} / \mathrm{dL})$ & $1.30 \pm 0.67$ & $1.29 \pm 0.69$ & .86 \\
\hline $\begin{array}{l}\text { Serum albumin at time of } \\
\text { listing }(\mathrm{g} / \mathrm{dL})\end{array}$ & $3.3 \pm 0.8^{*}$ & $3.7 \pm 0.7 *$ & $<.001^{*}$ \\
\hline Total bilirubin (mg/dL) & $1.9 \pm 1.7^{*}$ & $1.0 \pm 1.6^{*}$ & $<.001 *$ \\
\hline History of smoking & $37(34.6) *$ & $3242(52.7)^{*}$ & $<.001 *$ \\
\hline $\begin{array}{l}\text { Previous cardiac surgery } \\
\text { CABG } \\
\text { Valve } \\
\text { CABG } \pm \text { valve } \\
\text { Congenital } \\
\text { Others } \\
\text { None }\end{array}$ & $\begin{aligned} 21 & (19.6)^{*} \\
7 & (6.5)^{*} \\
1 & (0.9)^{*} \\
9 & (8.4)^{*} \\
8 & (7.5)^{*} \\
61 & (57.0)^{*}\end{aligned}$ & $\begin{aligned} & 831(13.5)^{*} \\
& 286(4.7)^{*} \\
& 100(1.6)^{*} \\
& 36(0.6)^{*} \\
& 1647(26.8)^{*} \\
& 3248(52.8)^{*}\end{aligned}$ & $<.001 *$ \\
\hline Cardiac output (L/min) & $4.0 \pm 1.7^{*}$ & $4.8 \pm 1.5^{*}$ & $<.001 *$ \\
\hline $\begin{array}{l}\text { Mean pulmonary artery } \\
\text { pressure }(\mathrm{L} / \mathrm{min})\end{array}$ & $29.1 \pm 10.3^{*}$ & $26.5 \pm 10.1^{*}$ & $.023 *$ \\
\hline $\begin{array}{l}\text { Mean pulmonary artery } \\
\text { wedge pressure }(\mathrm{L} / \mathrm{min})\end{array}$ & $20.7 \pm 9.9^{*}$ & $16.9 \pm 9.0^{*}$ & $<.001 *$ \\
\hline
\end{tabular}

TABLE 1. Continued

\begin{tabular}{lccc}
\hline \multicolumn{1}{c}{ Characteristic } & $\begin{array}{c}\text { ECMO } \\
(\mathbf{n}=\mathbf{1 0 7})\end{array}$ & $\begin{array}{c}\text { CF-LVAD } \\
(\mathbf{n = 6 1 4 8})\end{array}$ & $\begin{array}{c}\boldsymbol{P} \\
\text { value }\end{array}$ \\
\hline $\begin{array}{l}\text { Pulmonary vascular } \\
\text { resistance (Woods units) }\end{array}$ & $2.76 \pm 1.96$ & $2.31 \pm 1.73$ & $.042^{*}$ \\
Mechanical ventilation & $42(39.3)^{*}$ & $43(0.7)^{*}$ & $<.001^{*}$ \\
\hline IABP & $26(24.3)^{*}$ & $62(1.0)^{*}$ & $<.001^{*}$ \\
Inotropes & $66(61.7)^{*}$ & $479(7.8)^{*}$ & $<.001^{*}$ \\
\hline
\end{tabular}

Values are presented as mean \pm standard deviation or $\mathrm{n}(\%) . E C M O$, Extracorporeal membrane oxygenation; $C F-L V A D$, continuous-flow left ventricular assist device; $M E L D$-XI, model for end-stage liver disease excluding international normalized ratio, $C V A$, cerebrovascular accident; $C A B G$, coronary artery bypass grafting; $I A B P$, intraaortic balloon pump. *Statistically significant value $(P<.05) . \dagger$ MELD-XI $=11.76$ $\left(\log _{\mathrm{e}}\right.$ creatinine $)+5.112\left(\log _{\mathrm{e}}\right.$ total bilirubin $)+9.44$.

ischemic etiology, black race, gender mismatch, donor-recipient weight ratio, ischemic time, donor age, pulmonary vascular resistance, antibiotics administration, history of smoking, diabetes, educational level, steroid use, transfusions while waiting, distance from donor hospital to transplant center, donor ejection fraction, donor episode of cardiac arrest, donor cocaine use, donor tattoos, and expanded criteria donor. ${ }^{9}$ The 6148 patients with CF-LVAD were matched against a sample of 107 patients with ECMO; 82 matched pairs $(n=164)$ of CF-LVAD and ECMO patients were thus identified and were compared. Matching used a caliper size equal to 0.2 times the standard deviation of the estimated log propensity scores. Variable imbalance was compared between ECMO and CF-LVAD groups with absolute standardized difference of mean testing. Those variables with residual imbalance, defined as a standardized difference of mean $>0.10$, and treatment variable were entered into logistic and Cox regressions among the 164 matched patients as double robust methods to identify and eliminate bias. Clinical parameters before transplantation were analyzed to determine contributing factors using logistic regression for 90-day mortality and Cox proportional hazards models for 3-year mortality. List of variables entered in the analyses is shown in Table E9. For multivariable analyses, variables with a $P$ value $\leq .25$ on univariable analysis were included into a final multivariable model. The proportional hazard assumption was checked using Cox regression model with timedependent covariates. There was no evidence of violation of the proportional hazards assumption in our models (Table E9). Results are presented as odds ratio or hazard ratio (HRs) with corresponding 95\% CIs. All $P$ values were results of 2-tailed tests. The statistical analysis was performed using IBM-SPSS Statistics for Windows version 22.0 (IBM-SPSS Inc, Armonk, NY) and R version 2.15.3 (R Foundation for Statistical Computing, Vienna, Austria).

\section{RESULTS}

\section{Baseline Characteristics: Recipient}

Recipient clinical characteristics for each group are shown in Table 1. Patients in the ECMO group were younger; more likely to be a woman, nondiabetic, nonsmoker, and blood type A; more likely to have severely disabled/moribund functional status, inotropic support, and intra-aortic balloon pump; and more frequently mechanically ventilated at time of transplant than were patients in CF-LVAD group. The mean total time on the waitlist was shorter in ECMO group than CF-LVAD group. Additionally, patients in ECMO group more likely to have congenital heart disease as primary etiology, although less likely to have ischemic etiology compared with patients in the 
CF-LVAD group. Furthermore, ECMO group demonstrated higher MELD-XI score and lower serum albumin level. As for hemodynamic parameters, patients with ECMO had lower cardiac output with higher mean pulmonary artery pressure, pulmonary artery wedge pressure, and pulmonary vascular resistance than did patients in the CF-LVAD group. At time of listing on the waitlist, $40(37.4 \%)$ patients in the ECMO group were already on ECMO support.

\section{Baseline Characteristics: Donor}

Donor clinical characteristics for each group are shown in Table 2. Patients with ECMO more likely received a heart from an oversized donor and a long-distance donor heart than did patients with a CF-LVAD, whereas there was no difference in ischemic times. Gender mismatch was more frequent in ECMO group, particularly female donor-male recipient mismatch.

\section{Posttransplant Survival}

Kaplan-Meier analysis demonstrated estimated posttransplant survival of $73.1 \% \pm 4.4 \%$ versus $93.1 \% \pm 0.3 \%$ at 90 days $(P<.001)$ and $67.4 \% \pm 4.9$ versus $82.4 \% \pm 0.6 \%$ at 3 years $(P<.001)$ in the ECMO and CF-LVAD groups, respectively (Figure 1, $A$ ). In contrast, the survival was comparable between groups with the exclusion of patients who died or were censored within 90 days (Figure E1).

Propensity score matching resulted in 82 well-matched pairs of ECMO and CF-LVAD patients (Table 3). None of these covariates with residual imbalance appeared significant on the double-robust logistic and Cox regressions fitted to those variables and treatment variable (ECMO)
(Table E10). Postmatching analysis still demonstrated a lower survival rate in ECMO group at 90 days $(74.8 \% \pm 4.9 \%$ vs $88.8 \% \pm 3.5 \% ; P=.025)$ and 3 years $(69.3 \% \pm 5.5 \%$ vs $82.2 \% \pm 4.6 \% ; P=.054$ ) (Figure $1, B$ ). Additionally, propensity score matching only inclusive of variables without missing data was performed for reference in view of the high rate of missing data. Ninety-three matched pairs were identified and compared in the same fashion. The results are shown in Table E11 and Figure E2. The survival was similarly lower in ECMO group.

\section{Posttransplant Adverse Events/Causes of Death}

Posttransplant adverse events are listed in Table 4. Cerebrovascular accident and the need for dialysis were more often observed in ECMO group, whereas pacemaker placement was more frequent in the CF-LVAD group. The overall rate of graft failure was not different between groups; however, primary graft dysfunction was more frequently observed in the ECMO group. In addition, posttransplant functional status was more compromised in the ECMO group. As for the comparison of primary causes of death between groups, the most common causes of death were graft failure and multiorgan failure in the ECMO group and cardiovascular causes and infection in the CF-LVAD group (Table 5).

In contrast, as seen in Tables 4 and 5, adverse events and causes of death in the 82 propensity-matched patients were comparable.

\section{Contributors to Posttransplant Mortality in the ECMO Group}

Among the 107 ECMO patients, model for end-stage liver disease excluding international normalized ratio

TABLE 2. Baseline donor characteristics

\begin{tabular}{|c|c|c|c|}
\hline Characteristic & $\operatorname{ECMO}(n=107)$ & CF-LVAD $(n=6148)$ & $P$ value \\
\hline Female & $39(36.4)^{*}$ & $1423(23.1)^{*}$ & $.001 *$ \\
\hline Gender mismatch & & & $.003 *$ \\
\hline Male donor to female recipient & $21(19.6)^{*}$ & $773(12.6)^{*}$ & \\
\hline Female donor to male recipient & $16(15.0)^{*}$ & $527(8.6)^{*}$ & \\
\hline No gender mismatch & $70(65.4)^{*}$ & $4848(78.9)^{*}$ & \\
\hline Trauma as cause of death & $55(51.4)$ & $3437(55.9)$ & .35 \\
\hline Body mass index & $26.7 \pm 5.9$ & $27.6 \pm 5.7$ & .087 \\
\hline Age & $32.6 \pm 13.0$ & $31.4 \pm 11.0$ & .35 \\
\hline Donor-to-recipient weight ratio & & & $<.001 *$ \\
\hline$<0.8$ (undersized donor) & $15(14.0)^{*}$ & $994(16.2)^{*}$ & \\
\hline $0.8-1.2$ & $59(55.1)^{*}$ & $4197(68.3)^{*}$ & \\
\hline$>1.2$ (oversized donor) & $33(30.8)^{*}$ & $957(15.6)^{*}$ & \\
\hline Expanded criteria donor $\dagger$ & $2(1.9)$ & $158(2.6)$ & .65 \\
\hline Distance from donor hospital to transplant center (miles) & $244 \pm 285^{*}$ & $160 \pm 197$ & $<.001 *$ \\
\hline Ischemic time (hours) & $3.4 \pm 1.2$ & $3.2 \pm 1.1$ & .21 \\
\hline
\end{tabular}

Values are presented as mean \pm standard deviation or $\mathrm{n}(\%)$. ECMO, Extracorporeal membrane oxygenation; $C F-L V A D$, continuous-flow left ventricular assist device. *Statistically significant value $(P<.05)$. †Donors who are aged 60 years or older or who are between ages 50 and 59 years with at least 2 of the following conditions: history of hypertension, stroke as cause of death, and serum creatinine $>1.5 \mathrm{mg} / \mathrm{dL}{ }^{8}$ 

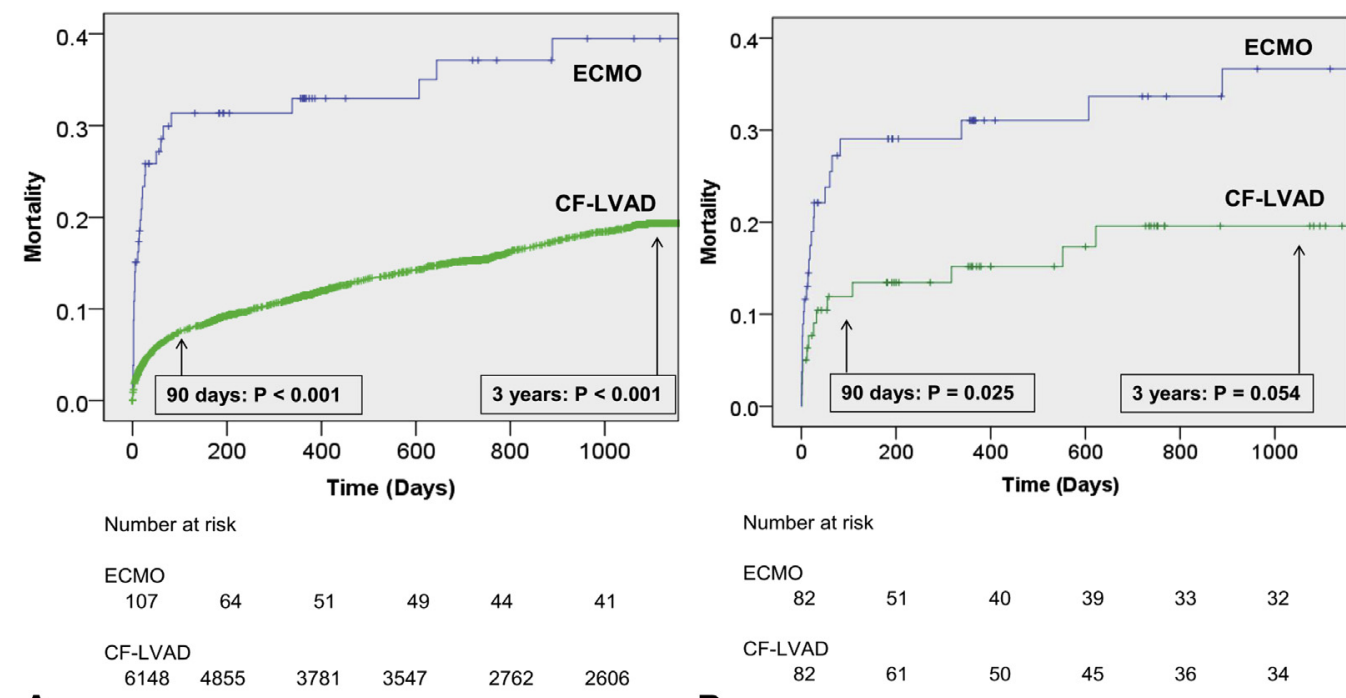

Number at risk

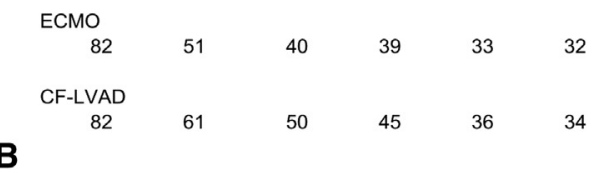

FIGURE 1. Kaplan-Meier curves for 90-day and 3-year posttransplant mortality: patients with extracorporeal membrane oxygenation (ECMO) versus patients with continuous-flow left ventricular assist device $(C F-L V A D)$. A, Before propensity matching. B, After propensity matching.

(MELD-XI) score was the sole contributor to both 90-day (odds ratio, 1.94 per 5-point of increase; $95 \%$ CI, 1.00-3.76; $P=.050)$ and 3-year mortality (HR, 1.47 per 5-point of increase; $95 \% \mathrm{CI}, 1.16-1.88 ; P=.002)$ in the multivariable logistic and Cox regression analyses. Additionally, mechanical ventilation at time of transplant (HR, 1.91; 95\% CI, 0.94-3.90; $P=.075$ ) showed a trend toward increased 3-year mortality.

ECMO-supported patients with a high MELD-XI (>17 [67th percentile]) were associated with dismal posttransplant outcomes compared with those with a low MELD-XI score $(<13$ [33rd percentile]) (90-day survival, $54 . \% \pm 8.8 \%$ vs $85.0 \% \pm 6.2 \%[P<.001]$ and 3 -year survival, $49.5 \% \pm 9.4 \%$ vs $73.5 \% \pm 8.2 \%[P<.001])$ (Figure 2).

\section{DISCUSSION}

We have studied the outcomes of adult patients on ECMO support directly bridged to heart transplant using the UNOS registry. We compared these results with those of patients bridged with CF-LVADs - the most commonly implanted hardware as BTT. The primary findings of interest in this study were: patients in the ECMO group were younger but much sicker than those in the CF-LVAD group, the early and midterm posttransplant survival in the ECMO group were inferior, the early/midterm posttransplant survival in the ECMO group remained inferior compared with CF-LVAD group even after propensity matching, and ECMO-supported patients with high MELD-XI score at time of transplant were associated with dismal posttransplant outcomes.

The current standard form of BTT in adults in the Unites States is an implantable durable ventricular assist device. Given the efficacy and durability, CF-LVAD use has continued to rise at a rapid pace. CF-LVAD is also shown to improve functional status and quality of life, ${ }^{9}$ whereas ECMO, in general, requires immobilization and mandates intensive monitoring in an intensive care unit. Owing to small body size and its versatilities, ECMO remains the mainstay as a BTT in pediatric populations. ${ }^{10}$ In contrast, the use of ECMO as a direct bridge to heart transplantation in adults has been extremely infrequent, except for posttransplant graft failure, with earlier small series showing poor outcomes, ${ }^{4,11,12}$ although these results were from 1980s, even before the era of first-generation CF-LVADs. In addition, the allotted time for medical and social evaluation for transplantation of ECMO-supported patients may be extremely limited due to ECMO-related complications. Consequently, the BTT pathway from ECMO in adult populations has remained controversial.

The 2006 revision of the UNOS/OPTN allocation system has demonstrated positive effect and improvement in outcomes; however, the UNOS/OPTN Thoracic Committee identified major issues with the existing allocation system, ${ }^{5,13}$ mainly originating from the expansion of ventricular assist device use as a BTT, which has changed the landscape of heart allocation. Among the most significant changes in the new proposed allocation system is patients with ECMO being assigned to the highest status. ${ }^{5}$ The major concern regarding this new system includes reduction of posttransplant survival by preferentially allocating hearts to ECMO-supported patients, although this may reduce waitlist mortality. In addition, the status 1 priority granted to ECMO patients may lead to an overuse of this pathway. On the contrary, there has been only a handful of small series in the literature regarding the posttransplant survival among ECMO-supported recipients. Unfortunately, these study results are significantly limited 
TABLE 3. Comparison of covariate imbalance between extracorporeal membrane oxygenation (ECMO) and continuous-flow left ventricular assist device (CF-LVAD) groups in the propensity-score matched sample

\begin{tabular}{|c|c|c|c|}
\hline Covariate & $\operatorname{ECMO}(n=82)$ & CF-LVAD $(n=82)$ & $\begin{array}{l}\text { Absolute standardized } \\
\text { difference of means }\end{array}$ \\
\hline Recipient age & $46.6 \pm 14.3$ & $48.6 \pm 13.8$ & 0.14 \\
\hline Donor age & $33.8 \pm 13.3$ & $33.3 \pm 12.4$ & 0.04 \\
\hline Status $1 \mathrm{~A}$ & $74(90.2)$ & $75(91.5)$ & 0.05 \\
\hline Ischemic etiology & $27(32.9)$ & $29(35.4)$ & 0.05 \\
\hline MELD-XI & $15.5 \pm 6.0$ & $16.1 \pm 7.5$ & 0.09 \\
\hline Totally dependent functional status & $66(80.5)$ & $63(76.8)$ & 0.09 \\
\hline Black race & $14(17.1)$ & $16(19.5)$ & 0.04 \\
\hline Dialysis & $6(7.3)$ & $7(8.5)$ & 0.04 \\
\hline Diabetes & $14(17.1)$ & $20(24.4)$ & 0.18 \\
\hline Mechanical ventilation & $19(23.2)$ & $16(19.5)$ & 0.09 \\
\hline IABP & $14(17.1)$ & $14(17.1)$ & 0.00 \\
\hline Inotropes & $45(54.9)$ & $42(51.2)$ & 0.07 \\
\hline Pulmonary vascular resistance & $2.43 \pm 1.73$ & $2.43 \pm 1.38$ & 0.00 \\
\hline Female gender & $25(30.5)$ & $27(32.9)$ & 0.09 \\
\hline $\begin{array}{l}\text { Gender mismatch } \\
\text { Male donor to female recipient } \\
\text { Female donor to male recipient }\end{array}$ & $\begin{array}{l}14(17.1) \\
11(13.4)\end{array}$ & $\begin{array}{l}16(19.5) \\
11(13.4)\end{array}$ & 0.06 \\
\hline Antibiotics before transplant & $15(18.3)$ & $16(19.5)$ & 0.03 \\
\hline History of smoking & $31(37.8)$ & $31(37.8)$ & 0.00 \\
\hline College or higher education degree & $38(46.3)$ & $31(37.8)$ & 0.17 \\
\hline Chronic steroid use & $8(9.8)$ & $11(13.4)$ & 0.05 \\
\hline Transfusions & $38(46.3)$ & $42(51.2)$ & 0.09 \\
\hline Donor-to-recipient weight ratio & $1.06 \pm 0.27$ & $1.06 \pm 0.27$ & 0.00 \\
\hline Expanded criteria donor & $2(2.4)$ & $3(3.7)$ & 0.08 \\
\hline Ischemic time (h) & $3.4 \pm 1.1$ & $3.4 \pm 1.0$ & 0.00 \\
\hline Distance from donor hospital to transplant center & $230 \pm 218$ & $210 \pm 218$ & 0.09 \\
\hline Donor LVEF & $61.5 \pm 7.6$ & $60.5 \pm 7.4$ & 0.13 \\
\hline Donor episode of cardiac arrest & $4(4.9)$ & $7(8.5)$ & 0.14 \\
\hline Donor cocaine use & $9(11.0)$ & $10(12.2)$ & 0.04 \\
\hline Donor tattoos & $31(37.8)$ & $37(45.1)$ & 0.15 \\
\hline
\end{tabular}

Values are presented as mean \pm standard deviation or n (\%). ECMO, Extracorporeal membrane oxygenation; $C F-L V A D$, continuous-flow left ventricular assist device; $M E L D$-XI, model for end-stage liver disease excluding international normalized ratio; $I A B P$, intra-aortic balloon pump; $L V E F$, left ventricular ejection fraction.

because of the lack of details with a very small number of patients in each study. These reports are exclusively from non-US centers.

Jasseron and colleagues ${ }^{4}$ reported the use of transplantation as first-line therapy in 80 waitlisted transplant candidates on ECMO, of whom 46 actually underwent transplant. ${ }^{4}$ This retrospective study using the data from the French national registry CRISTAL was the largest previous series describing the outcomes of ECMO as a BTT. This study was unique in terms of comparing transplanted ECMO patients with those who remained on the waitlist. The median duration of ECMO support was 9 days (interquartile range, 6-15 days) with 1-year posttransplant survival rate of $70.4 \%$, whereas $28 \%$ among those did not receive transplant. The detail of the waitlist mortality was not described in their report. Rousse and colleagues $^{14}$ from France reported their ECMO use as a bridge to decision. In their series, 13 ECMO-supported patients ( 1 postcardiotomy shock, 8 dilated/ischemic cardiomyopathy, and 4 acute myocardial infarction) were bridged to transplantation with 1-year posttransplant survival rate of $51 \%{ }^{14}$ The duration of pretransplant 
TABLE 4. Posttransplant adverse events before and after propensity-score matching

\begin{tabular}{|c|c|c|c|c|c|c|}
\hline & \multicolumn{3}{|c|}{ Before propensity match } & \multicolumn{3}{|c|}{ After propensity match } \\
\hline & $\begin{array}{c}\text { ECMO } \\
(\mathbf{n}=107)\end{array}$ & $\begin{array}{l}\text { CF-LVAD } \\
(n=6148)\end{array}$ & $P$ value & $\begin{array}{c}\text { ECMO } \\
(n=82)\end{array}$ & $\begin{array}{c}\text { CF-LVAD } \\
(\mathrm{n}=82)\end{array}$ & $P$ value \\
\hline Graft failure & $8(7.5)$ & $366(6.0)$ & .51 & $6(7.3)$ & $7(8.5)$ & .77 \\
\hline Primary & $6(5.6)^{*}$ & $132(2.1)^{*}$ & $.016^{*}$ & $5(6.1)$ & $5(6.1)$ & 1.00 \\
\hline Acute/chronic rejection & $2(1.9)$ & $130(2.1)$ & .86 & $1(1.2)$ & $2(2.4)$ & 1.00 \\
\hline Others & 0 & $104(1.7)$ & .18 & 0 & 0 & \\
\hline Episode of rejection & $25(24.3)$ & $1154(18.8)$ & .16 & $20(24.4)$ & $17(20.7)$ & .58 \\
\hline Functional status at the most recent follow-up & & & $<.001 *$ & & & .20 \\
\hline Total assistance & $32(49.2)^{*}$ & $546(12.8)^{*}$ & & $22(44.9)$ & $15(27.8)$ & \\
\hline Some assistance & $5(7.7)^{*}$ & $681(15.9)^{*}$ & & $5(10.2)$ & $7(13.0)$ & \\
\hline No assistance & $28(43.1)^{*}$ & $3045(71.3)^{*}$ & & $22(44.9)$ & $32(59.3)$ & \\
\hline Pacemaker insertion & $0^{*}$ & $227(3.7)^{*}$ & $.034 *$ & 0 & $2(2.5)$ & .25 \\
\hline Renal insufficiency requiring dialysis & $22(21.2)^{*}$ & $684(11.3)^{*}$ & $.002 *$ & $14(17.1)$ & $9(11.0)$ & .26 \\
\hline CVA & $10(9.4)^{*}$ & $202(3.3)^{*}$ & $.001 *$ & $7(8.5)$ & $3(3.7)$ & .33 \\
\hline
\end{tabular}

Values are presented as n (\%). ECMO, Extracorporeal membrane oxygenation; $C F-L V A D$, continuous-flow left ventricular assist device; $C V A$, cerebrovascular accident. *Statistically significant value $(P<.05)$.

ECMO support was not described. Another report from France demonstrated the outcomes of 8 ECMO-supported patients with a mean age of 41 years receiving a heart transplant. ${ }^{15}$ The etiologies of cardiogenic shock were myocardial infarction in 2 patients, HIV-associated cardiomyopathy in 1 patient, and acute decompensated heart failure in 5 patients. The mean ECMO duration was 6.3 days and all patients were alive 1 year following transplantation despite a number of adverse events during the early postoperative period. A series from Taiwan reported on 15 patients supported with ECMO who were bridged to transplant. The mean duration of ECMO support was 9.2 days. Eleven $(73.3 \%)$ survived to hospital discharge and in further follow-up, survival was not reported. ${ }^{16}$ Mishra and colleagues ${ }^{17}$ from Norway reported on 15 ECMO patients with a mean age of 38 years who underwent BTT with 1-year survival of $70 \%$. The mean ECMO duration was 9.1 days. The etiologies of heart failure were dilated cardiomyopathy in 7 patients, ischemic heart disease in 5 patients, and other etiology in 3 patients.
Barge-Caballero and colleagues from Spain reported the influence of preoperative short-term MCS on posttransplant outcomes. ${ }^{18}$ Among the 101 patients in the short-term MCS cohort, $23(22.8 \%)$ were supported with ECMO. Preoperative bridging with ECMO did not carry a significant increase of posttransplant mortality in comparison with the non-BTT control group; however, the outcome detail in the ECMO group was not described in their report.

It appears that the ECMO BTT pathway is more common in France than in the United States. In France, prioritization for high-urgency transplantation (ie, special urgency) has been available for those meeting certain criteria (inotropes and/or ECMO with no implantable MCS) since $2004 .{ }^{15}$ The main objective of the special urgency status implementation was to maximize survival of the patients on the waiting list by allocating hearts to the sickest candidates with a national graft distribution. As a result, between 2004 and 2008, the number of patients who received a transplant through this pathway rose dramatically, and the mortality on the waiting list dropped from 307 to 231 deaths per 1000

TABLE 5. Primary causes of death in each group before and after propensity-score matching

\begin{tabular}{|c|c|c|c|c|c|c|}
\hline \multirow[b]{2}{*}{ Cause of death } & \multicolumn{3}{|c|}{ Before propensity matching } & \multicolumn{3}{|c|}{ After propensity matching } \\
\hline & $\overline{\operatorname{ECMO}(n=37)}$ & CF-LVAD $(n=1099)$ & $P$ value & $\overline{\operatorname{ECMO}(n=27)}$ & CF-LVAD $(n=14)$ & $P$ value \\
\hline Graft failure & $7(18.9)$ & $155(14.1)$ & .41 & $6(22.2)$ & $4(28.6)$ & .71 \\
\hline Infection & $3(8.1)$ & $181(16.5)$ & .20 & $3(11.1)$ & $2(14.3)$ & 1.00 \\
\hline Cardiovascular & $4(10.8)$ & $190(17.3)$ & .18 & $2(7.4)$ & $2(14.3)$ & .60 \\
\hline Pulmonary & $1(2.7)$ & $62(5.6)$ & .44 & 0 & 0 & 1.00 \\
\hline CVA & $4(10.8)$ & $63(5.7)$ & .28 & $3(11.1)$ & $2(14.3)$ & 1.00 \\
\hline Multiorgan failure & $10(27.0)^{*}$ & $136(12.4)^{*}$ & $.009 *$ & $6(22.2)$ & $2(14.3)$ & .69 \\
\hline Others & 8 (21.6) & $312(28.4)$ & .37 & 7 (25.9) & $2(14.3)$ & .69 \\
\hline
\end{tabular}

Values are presented as n (\%). ECMO, Extracorporeal membrane oxygenation; $C F-L V A D$, continuous-flow left ventricular assist device; $C V A$, cerebrovascular accident. * Statistically significant value $(P<.05)$. 


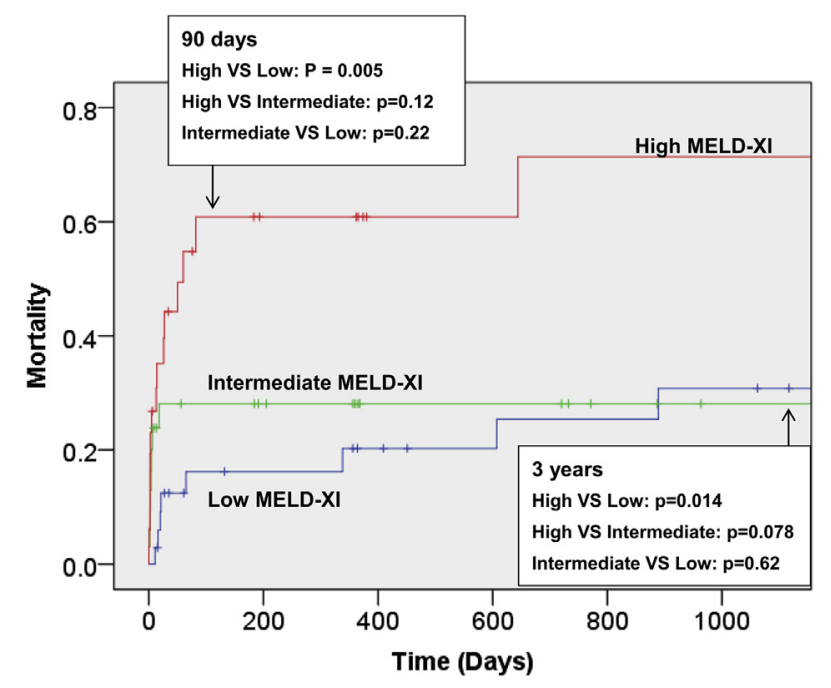

Number at risk

$\begin{array}{cccccc}\text { Low MELD-XI } & & & & \\ 36 & 25 & 22 & 20 & 19 & 17 \\ \text { Intermediate MELD-XI } & & & \\ 35 & 20 & 15 & 15 & 12 & 10 \\ \text { High MELD-XI } & & & & \\ 36 & 14 & 10 & 10 & 9 & 9\end{array}$

FIGURE 2. Kaplan-Meier curves for 90-day and 3-year posttransplant mortality among patients with extracorporeal membrane oxygenation (ECMO) stratified by model for end-stage liver disease excluding international normalized ratio (MELD-XI) score (low MELD-XI, <13; intermediate MELD-XI, 13-17; and high MELD-XI, >17).

patient-years, whereas the shortage of donor hearts remained stable. However, 1-year posttransplant survival dropped significantly from $77 \%$ to $71 \%{ }^{19}$ This raises the question of the limitation of a graft allocation system that prioritizes candidates at critical risk for death and bypassing use of durable MCS as BTT. ${ }^{19}$ The proportion of recipients using a durable ventricular assist device and ECMO between France and the United States is strikingly different. For instance, in 2013 in France were 13\% and 15\%, respectively, ${ }^{4}$ as opposed to $35 \%$ (only inclusive of CF-LVAD) and $0.2 \%$ in 2013 from this UNOS dataset.

Overuse of ECMO may possibly occur under the new cardiac allocation system based on medical urgency, which is solely defined by therapies without considering other objective patient factors. Objective candidate risk score, providing prediction of posttransplant mortality, is an option to address this specific issue. In the present study, receiving heart transplantation during ECMO support was associated with increased early/midterm posttransplant mortality compared with those supported with CF-LVAD. This survival difference is primarily driven by the difference in the early mortality because the survival was comparable after exclusion of early mortality (Figure E2). Patients with a high MELD-XI score (ie, >17) demonstrated a particularly worse survival, exceeding

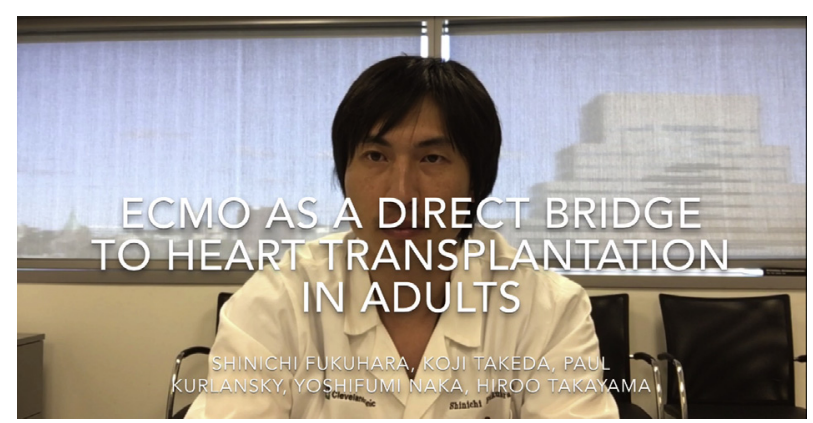

VIDEO 1. Introduction and brief overview of the present study by 1 of the authors. Video available at: http://www.jtcvsonline.org/article/S00225223(17)33002-7/fulltext.

$50 \%$ at 3 years after transplant. Hepatorenal function is known to greatly influence successful transplant outcomes. A strong association between MELD-XI and survival was evident among patients undergoing BTT with a CF-LVAD in the present study (Figure E3) and from previous studies. $^{7,20}$ This fact may have important implications in selecting transplant recipients in the presence of ECMO support. In such situations, CF-LVAD insertion as bridge-to-bridge support for these critically unwell ECMO patients might be a more suitable pathway than transplantation (Video 1).

\section{Study Limitations}

This study has some recognized limitations and our results should be interpreted with caution. First, our investigation is retrospective nature. Some findings in the dataset are clinically nonintuitive, such as several ECMO patients not being status $1 \mathrm{~A}$ at time of transplant. According to UNOS, very occasionally status in the dataset does not reflect the true history of the recipient. Additionally, no particular trend regarding the cause of death was identified despite the unfavorable survival in the ECMO group. This is partially because cause of death classification can be ambiguous in many clinical settings. Second, many fields in the database contain varying proportions of missing values, which are almost always a significant problem in analyses of large multi-institutional databases and the UNOS registry in particular. Simply excluding cases with a significant amount of missing data for the analysis can critically influence the results. To address this issue, we performed multiple imputations, which are considered the gold standard for handling missing data and its potential problems. Third, there are many other clinical variables not in the UNOS registry that can adversely influence posttransplant outcomes. Given the discrepancy in the cohort size between groups, propensity matching using a matching ratio higher than 1:1 was preferred; however, extreme imbalance between groups in certain variables did not allow a higher ratio matching. Forth, the present study did not evaluate the waitlist mortality of patients on ECMO support. Furthermore, the most crucial 
question would be whether patients supported with ECMO should receive a transplant directly or a CF-LVAD (bridge to bridge). However, such comparison was not possible with the available UNOS dataset. Finally, the posttransplant follow-up period was limited to 3 years simply because not so many patients have been followed beyond 3 years. Additional studies with longer follow-up intervals are warranted.

\section{CONCLUSIONS}

The evolving LVAD technology has led to significant shifts in patient outcomes and influenced the cardiac allocation system. With the new allocation system, where ECMOsupported patients receive the highest priority, posttransplant survival may be compromised, given the results of the present study. Under such circumstances, careful candidate selection by each transplant program is of paramount importance because patients with evidence of end-organ dysfunction despite ECMO support may not qualify for transplantation. Further studies are needed to more objectively determine patient risk profile, more appropriately select candidates, and ultimately optimize the allocation system.

\section{Webcast}

You can watch a Webcast of this AATS meeting presentation by going to: https://aats.blob.core.windows.net/media/ 17AM/2017-05-02/RM306/05-02-17_Room306_1629_ Fukuhara.mp4.

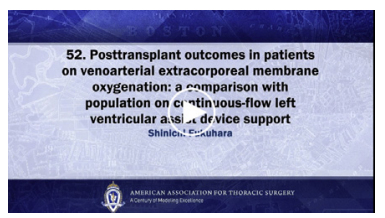

\section{Conflict of Interest Statement}

Dr Naka has been a consultant for Abbott. All other authors have nothing to disclose with regard to commercial support.

\section{References}

1. Fukuhara S, Takeda K, Polanco AR, Takayama H, Naka Y. Prolonged continuous-flow left ventricular assist device support and post-transplant outcomes: a new challenge. J Thorac Cardiovasc Surg. 2016;151:872-80.e1-5.

2. McCarthy FH, McDermott KM, Kini V, Gutsche JT, Wald JW, Xie D, et al. Trends in U.S. extracorporeal membrane oxygenation use and outcomes: 20022012. Semin Thorac Cardiovasc Surg. 2015;27:81-8.

3. Thiagarajan RR, Barbaro RP, Rycus PT, Mcmullan DM, Conrad SA, Fortenberry JD, et al. Extracorporeal Life Support Organization Registry international report 2016. ASAIO J. 2017;63:60-7.

4. Jasseron C, Lebreton G, Cantrelle C, Legeai C, Leprince P, Flecher E, et al. Impact of heart transplantation on survival in patients on venoarterial extracorporeal membrane oxygenation listing in France. Transplantation. 2016;100:1979-87.

5. OPTN/UNOS policy notice proposal to modify the Adult Heart Allocation System. Available at: https://optn.transplant.hrsa.gov/media/1244/08_adult_ heart_allocation_part1.pdf. Accessed April 22, 2017.

6. Karnofsky DA, Burchenal JH. The clinical evaluation of chemotherapeutic agents in cancer. In: MacLeod CM, ed. Evaluation of Chemotherapeutic Agents. New York, NY: Columbia University Press; 1949:191-205.
7. Deo SV, Al-Kindi SG, Altarabsheh SE, Hang D, Kumar S, Ginwalla MB, et al. Model for end-stage liver disease excluding international normalized ratio (MELD-XI) score predicts heart transplant outcomes: evidence from the Registry of the United Network for Organ Sharing. J Heart Lung Transplant 2016;35:222-7.

8. Demirtas H, Freels SA, Yucel RA. Plausibility of multivariate normality assumption when multiply imputing non-Gaussian continuous outcomes: a simulation assessment. J Stat Comput Simulat. 2008;78:69-84.

9. Baskin-Bey ES, Kremers W, Stegall MD, Nyberg SL. United Network for Organ Sharing's expanded criteria donors: is stratification useful? Clin Transplant. 2005;19:406-12.

10. Dipchand AI, Mahle WT, Tresler M, Naftel DC, Almond C, Kirklin JK, et al Extracorporeal membrane oxygenation as bridge to pediatric heart transplantation: effect on post-listing and post-transplantation outcomes. Circ Heart Fail. 2015;8: 960-9.

11. Pennington DG, McBride LR, Kanter KR, Miller LW, Ruzevich SA Naunheim K, et al. Bridging to heart transplantation with circulatory support devices. J Heart Transplant. 1989;8:116-23.

12. Kolla S, Lee WA, Hirschl RB, Bartlett RH. Extracorporeal life support for cardiovascular support in adults. ASAIO J. 1996;42:M809-19.

13. Organ Procurement and Transplantation Network. Modify adult heart allocation 2016 2nd round. Available at: https://optn.transplant.hrsa.gov/governance/publiccomment/modify-adult-heart-allocation-2016-2nd-round. Accessed April 20, 2017

14. Rousse N, Juthier F, Pinçon C, Hysi I, Banfi C, Robin E, et al. ECMO as a bridge to decision: recovery, VAD, or heart transplantation? Int J Cardiol. 2015;187:620-7.

15. Barth E, Durand M, Heylbroeck C, Rossi-Blancher M, Boignard A, Vanzetto G, et al. Extracorporeal life support as a bridge to high-urgency heart transplantation. Clin Transplant. 2012;26:484-8.

16. Chung JC, Tsai PR, Chou NK, Chi NH, Wang SS, Ko WJ. Extracorporeal membrane oxygenation bridge to adult heart transplantation. Clin Transplant. 2010; 24:375-80.

17. Mishra V, Fiane AE, Winsnes BA, Geiran O, Sørensen G, Hagen TP, et al. Cardiac replacement therapies: outcomes and costs for heart transplantation versus circulatory assist. Scand Cardiovasc J. 2017;51:1-7.

18. Barge-Caballero E, Almenar-Bonet L, Villa-Arranz A, Pérez-Villa F, SegoviaCubero J, Delgado-Jiménez J, et al. Impact of short-term mechanical circulatory support with extracorporeal devices on postoperative outcomes after emergency heart transplantation: data from a multi-institutional Spanish cohort. Int $J$ Cardiol. 2014;176:86-93.

19. Dorent R, Epailly E, Sebbag L. The effect of graft allocation system on outcomes in heart transplantation in France: has the time come to take calculated survival benefit into account? J Heart Lung Transplant. 2011;30:1299-300.

20. Fukuhara S, Takeda K, Blair A, Kurlansky PA, Takayama H, Naka Y. Posttransplant outcomes among septuagenarians bridged to transplantation with continuous-flow left ventricular assist devices. Ann Thorac Surg. 2017;103:41-8.

Key Words: heart transplant, bridge-to-transplant, endstage heart failure, donor organ allocation system

\section{Discussion}

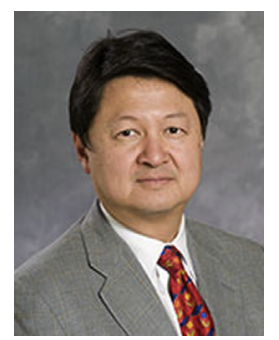

Dr Benjamin Sun (Minneapolis, Minn). This is a really timely publication and presentation because of the impending United Network for Organ Sharing (UNOS) allocation, which, as you stated, prioritizes extracorporeal membrane oxygenation (ECMO) as among the most accelerated patients who will receive grafts.

I have 3 questions related to this because this is part of our balance of understanding the risk of dying on the wait list versus the risk of dying after a transplant. The first is that this is a span of about 14 years of data, and there are 2 
eras of ECMO that it covers. There is, as Dr Bartlett says, ECMO 1 and ECMO 2, and ECMO 2, which is the more recent with our better circuits and better oxygenators in particular, has led to a lot more ECMO use recently as well as better outcomes. As you were looking at your data, did you see a trend toward improved outcomes in the last 6 or 7 years, let's say 2010 to now, compared with the earlier parts, 2003 to 2010 ?

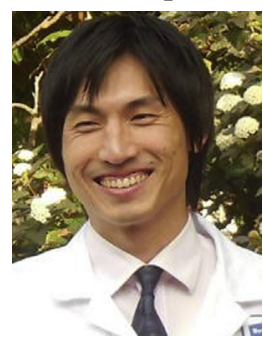

Dr Shinichi Fukuhara (New York, $N Y$ ). We didn't see any obvious difference between the first and the second era you described, and as I showed, the continuous left ventricular assist device (LVAD) group was basically consistent with good outcomes throughout this study period.

Dr Sun. And that may just partly be because the people who actually were bridged were a very uniform population for whom technology may not have changed. That's number 1.

Number 2, of the patients who were bridged to transplant with ECMO, as I reviewed your article, there were 120 days between listing in the ECMO group to transplant, with 40 of them being listed at the time of ECMO. Do you know what the mean support time on ECMO was before receiving a heart transplant?

Dr Fukuhara. This is a very good point and thank you so much for raising this point. Actually, as you mentioned, about $40 \%$ of patients in the ECMO cohort were already on ECMO at the time of listing. I calculated specifically the duration of wait list time for the subgroup. In fact, most patients were $<10$ days; however, there are several patients who were on wait lists for 2 or even 3 months. What I thought was probably some patients were on ECMO originally, came off once, and they were put back on ECMO. This is just my assumption. I couldn't tell exactly what happened in these patients from this dataset.

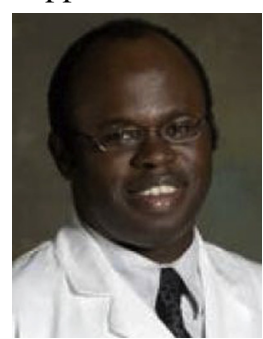

Dr Anelechi C. Anyanwu (New York, $N Y$ ). Just to clarify, the ECMO coding in the UNOS database, is it ECMO at time of listing or ECMO at time of transplant? What is the code in the UNOS database?

Dr Fukuhara. It has both, ECMO at the time of listing and ECMO at the

time of transplant.

Dr Anyanwu. And for the purpose of your study, which definition did you use?

Dr Fukuhara. This is ECMO at the time of transplant.

Dr Anyanwu. At the time of transplant?

Dr Fukuhara. Yes, that's correct. I didn't mention anything about ECMO at the time of registration.
Dr Sun. Because the current proposal is that the ECMO qualification for a status 1 will be for 14 days with a review at that point to determine the appropriateness of the ongoing therapy.

The final question I have, or maybe it's a comment, is the idea that this is going to be the newer incentive to get our patients transplanted. As it becomes more and more competitive, will ambulatory ECMO become among the ways that we evolve? As we have seen in our lung transplant colleagues, in fact, that it is almost a preferred approach for many patients? Do you see this as a potential for us down the road?

Again, a very timely and important topic to bring up.

Dr Fukuhara. Yes, that is very true, and this is also a great point. As I briefly mentioned, overuse of ECMO is a possibility that can occur in the foreseeable future, and probably fewer sick patients are being placed on ECMO for the purpose of getting a transplant. However, as I mentioned, patients who have obvious end-organ damage despite ECMO support are likely not good candidates for a transplant and a judicious use of ECMO by each transplant program is I think the key factor in the new allocation system.

Dr Anyanwu. Before we take your questions, can I just ask for a show of hands? How many people in the past year have transplanted a patient directly off ECMO?

(Show of hands)

Dr Anyanwu. Okay, a fair amount.

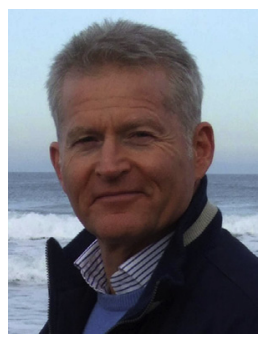

Dr Stephan W. Scheuler (Newcastle upon Tyne, United Kingdom). It is a nice effort to do a historic look at this topic. I think for the future, it is completely unacceptable to transplant patients from ECMO because of these results. You are wasting organs. You have perfect patients on your waiting list on LVADs who have normal kidney function, no problems at all. And in the present era with very good mechanical support devices, there is no justification, not a single 1 , not even in the congenital group where we documented that LVAD therapy works very well, durable devices so you can rescue them, transition them to durable devices, and let them go home to recover from their acute cardiac failure, and then transplant them and you will have good outcomes and you will not waste any donor hearts. That would be my comment to your findings.

A very good paper.

Dr Anyanwu. If I could ask someone in the audience who put their hand up to come to the microphone and respond to that. So why would you or did you transplant someone on ECMO? Anyone who put his or her hand up? 


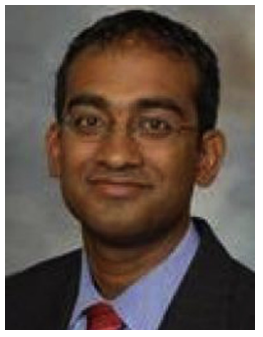

Dr Pavan Atluri (Philadelphia, Pa). I will tell you, it's very easy for us in our Organ Procurement Organization to get organs. I have never taken a patient who is at end-organ dysfunction and transplanted them, but someone who is a blood group A or a blood group B, I can very quickly transplant them. So for me, we have had excellent outcomes in that scenario and that's the reason why I did it.

Dr Anyanwu. So really the time is the issue. If you have to keep the patient on ECMO longer, you would switch to another bridging device, but you have not seen the need to do that?

Dr Atluri. Completely agree. Absolutely.

Dr Anyanwu. Are there any other reasons? What was your reason?

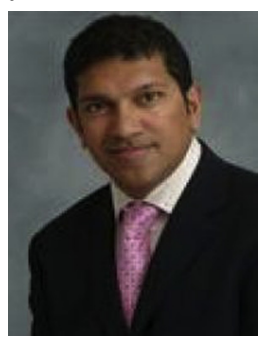

Dr Vivek Rao (Toronto, Ontario, Can$a d a)$. I was just going to say this to Ben: It's exactly that. So they come in at Interagency Registry for Mechanically Assisted Circulatory Support 1-you stabilize them on ECMO. We generally have a 5- to 7-day cut point where we give them a day to upgrade them, but we list them if they are extubated and neurologically intact, and if they get a heart within the 5 days, and often we do, especially if they are small As and Bs, then we will transplant them right off ECMO.

Dr Anyanwu. So your patients would have a low model for end-stage liver disease score?

Dr Rao. Yes, they have completely recovered and we are happy to list them and we will just say, Listen, if you don't get a heart by next Tuesday, we are going to put an assist device in you, but if you do, great. We would rather go straight to transplant and avoid the sensitization and everything else of the LVAD operation.

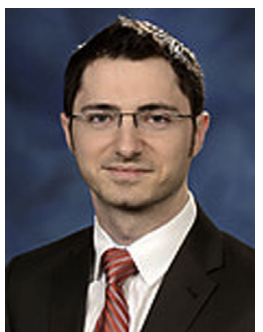

Dr Zachary N. Kon (Baltimore, $M d$ ). A propensity matching continuous flow LVAD to an ECMO group to me seems somewhat inappropriate because I think there are very few people who if a continuous flow device was a viable option for that patient cohort, they probably would not stay on ECMO as a bridge to transplant, particularly the ones who were out weeks as opposed to what most people are used to, which is a few days on ECMO, get them a quick organ, and turn them around.

There certainly is a cohort of patients who have biventricular failure, a hostile chest. You think a biventricular assist device or a total artificial heart is not a realistic approach and that patient could be bridged on ECMO to transplantation. At our center, we actually now have preferentially used ECMO for biventricular failure with fairly good results.

Dr Anyanwu. I think you have a time limit, so let's say they were on ECMO for 2 weeks or 3 weeks. Would you keep going?

Dr Kon. We don't have an arbitrary time limit. We have an end-organ function limit. So if you don't recover end-organ function, you don't become a candidate.

Dr Anyanwu. And roughly what percentage survive to transplantation?

Dr Kon. We just actually looked back at this and it's a little over $70 \%$ as a bridge to transplant. Now, we are very aggressive for rehabilitation. We are a big ECMO program. We walk people on venoarterial ECMO.

Again, ECMO is a tool, just like any other device, and if your center is very comfortable with it I think you can do very well.

Dr Anyanwu. What is the longest period on ECMO you have had as a benchmark?

Dr Kon. The longest for bridge to heart was 58 days.

Dr Anyanwu. David?

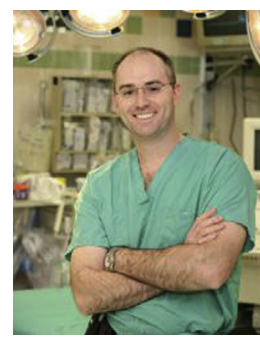

Dr David A. D'Alessandro (Boston, Mass). I can see there are some people who are very good at this, but can someone explain how when someone is new to your system that comes in with an acute process that goes on ECMO, how can you possibly work them up for transplant, know that they don't have a recoverable process, and then go to transplantation from that platform without cutting a lot of corners? I can see doing it on occasion, but as a routine it seems like we are changing our practice. I agree with your comments that we shouldn't be doing it.

Dr Anyanwu. Do you want to respond to that?

Dr Rao. This would be a patient who you already have on your list who comes in, so you have already worked them up.

Dr D'Alessandro. That makes a lot of sense, but that's not what I'm hearing is going on. They are often intubated, you can't discuss it with them, the family members are coming in there. We all have this process - the psychiatrist, the social worker, the financial planner-you have got to meet the family, the brothers and sisters. You are cutting a lot of corners by transplanting off ECMO.

Dr Rao. I agree. I think those people need to be upgraded. I think the next phase of this is to show, as was discussed, that if you bridge them from an ECMO to an LVAD that you eliminate that survival disadvantage of ECMO. I 
don't know if you can do it in UNOS but you can certainly do it with your Columbia database and show that a strategy of going from ECMO to an implantable LVAD to transplant has equivalent survival.
Dr Fukuhara. I think that is the most important question I had as well before I started doing this study, and actually I couldn't analyze bridge-to-bridge versus direct bridge-totransplant. The UNOS data did not allow me to do that.

Readers who found these articles interesting may also like to read the following papers found in recent and future issues of our sister publications, Seminars in Thoracic and Cardiovascular Surgery and Operative Techniques in Thoracic and Cardiovascular Surgery!

\section{Adult: Mechanical Circulatory Support}

ORIGINAL SUBMISSION: Central Cannulation as a Viable Alternative to Peripheral Cannulation in Extracorporeal Membrane Oxygenation. David N. Ranney. Semin Thoracic Surg 2017: 188-195.

Editorial Commentary: Primmum Nil Nocere, Second be Cautious and Third Try to Use the Right Extracorporeal Membrane Oxygenator Modality. D. Berdajs. Semin Thoracic Surg 2017: 196-197.

ORIGINAL SUBMISSION: Minimally Invasive Implantation: The Procedure of Choice! Jan D. Schmitto. Oper Tech Thorac Cardiovasc 2016: 65-78. 


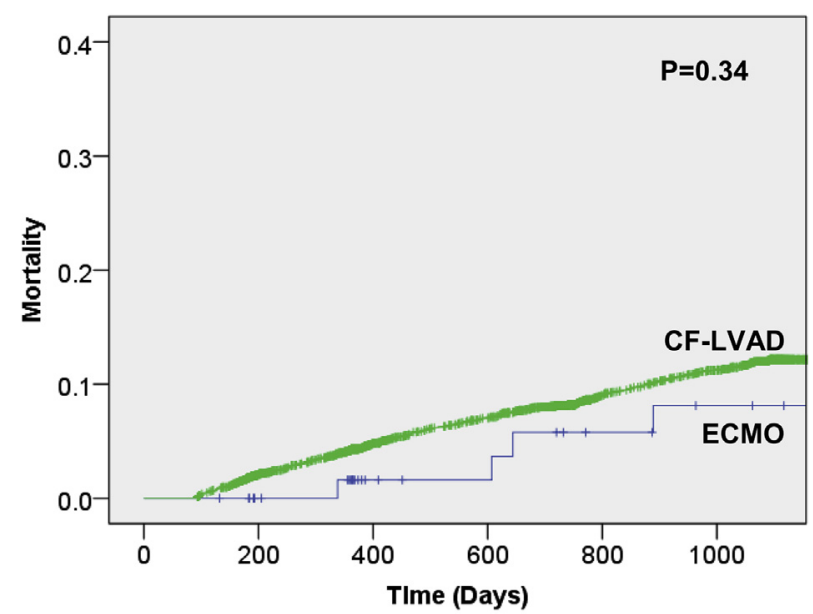

Number at risk

ECMO

\begin{tabular}{|c|c|c|c|c|c|}
\hline 69 & 63 & 51 & 47 & 44 & 41 \\
\hline \multicolumn{6}{|l|}{ CF-LVAD } \\
\hline 5337 & 4855 & 3781 & 3547 & 2762 & 2606 \\
\hline
\end{tabular}

FIGURE E1. Kaplan-Meier curves for 3-year posttransplant mortality after excluding patients who died or were censored within 90 days. ECMO, Extracorporeal membrane oxygenation; $C F-L V A D$, continuous-flow left ventricular assist device.

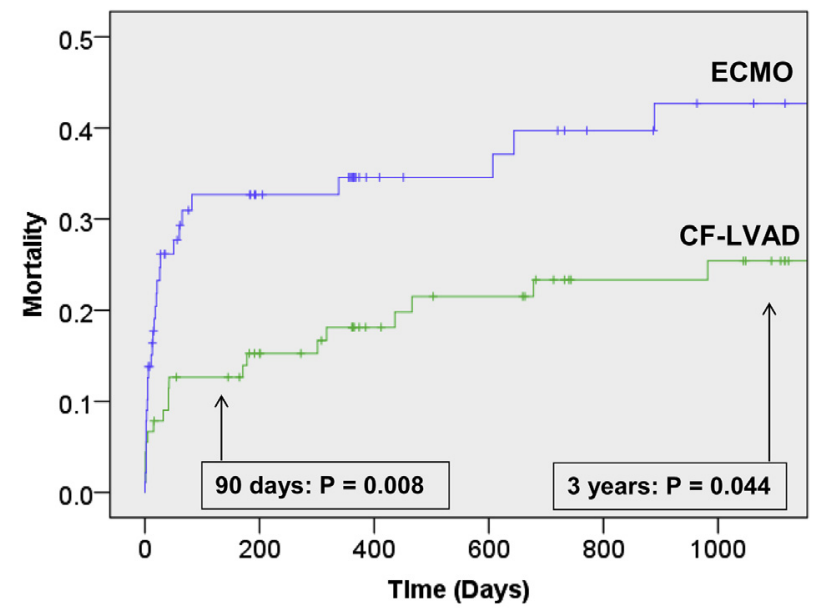

Number at risk

$\begin{array}{cccccc}\begin{array}{c}\text { ECMO } \\ 93\end{array} & 54 & 42 & 40 & 35 & 32 \\ \begin{array}{c}\text { CF-LVAD } \\ 93\end{array} & 73 & 61 & 58 & 49 & 48\end{array}$

FIGURE E2. Kaplan-Meier curves for 90-day and 3-year posttransplant mortality among the propensity-score matched patients after excluding variables with missing data. ECMO, Extracorporeal membrane oxygenation; $C F-L V A D$, continuous-flow left ventricular assist device.

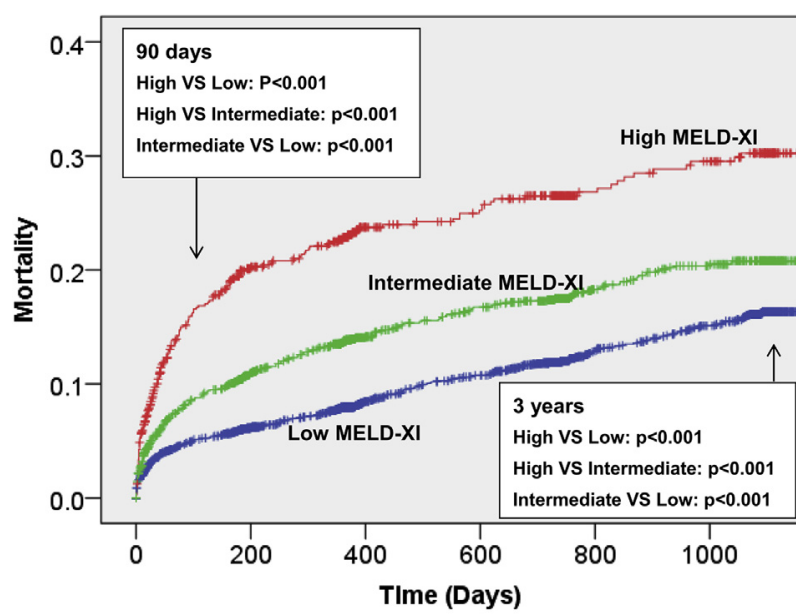

Number at risk

\begin{tabular}{|c|c|c|c|c|c|}
\hline \multicolumn{6}{|c|}{ Low MELD-XI } \\
\hline 3589 & 2925 & 2308 & 2182 & 1692 & 1595 \\
\hline \multicolumn{6}{|c|}{ Intermediate MELD-XI } \\
\hline 1696 & 1327 & 1019 & 938 & 744 & 698 \\
\hline \multicolumn{6}{|c|}{ High MELD-XI } \\
\hline 820 & 569 & 425 & 397 & 302 & 289 \\
\hline
\end{tabular}

FIGURE E3. Kaplan-Meier curves for 90-day and 3-year posttransplant mortality among patients with continuous-flow left ventricular assist device stratified by model for end-stage liver disease excluding international normalized ratio (MELD-XI) score. Low MELD-XI, <13; intermediate MELD-XI, 13-17; high MELD-XI, >17. 
TABLE E1. Corresponding $95 \%$ confidence interval (CI) in each time point for Kaplan-Meier curve (Figure 1, $A$ )

\begin{tabular}{llc}
\hline \multirow{2}{*}{ Time (d) } & \multicolumn{2}{c}{ Mortality $(\mathbf{9 5} \% \mathbf{C I})$} \\
\cline { 2 - 3 } 200 & $26.9(22.5-31.3)$ & CF-LVAD \\
\hline 400 & $28.1(23.7-32.5)$ & $8.8(8.4-9.2)$ \\
600 & $28.1(23.7-32.5)$ & $11.3(10.9-11.7)$ \\
800 & $29.5(24.9-34.1)$ & $13.3(12.8-13.8)$ \\
1000 & $32.6(27.7-37.5)$ & $14.9(14.4-15.4)$ \\
\hline$C I$, Confidence interval; $E C M O$, extracorporeal membrane oxygenation; $C F-L V A D$, \\
continuous-flow left ventricular assist device.
\end{tabular}

TABLE E2. Corresponding $95 \%$ confidence interval (CI) in each time point for Kaplan-Meier curve (Figure 1, B)

\begin{tabular}{llc}
\hline & \multicolumn{2}{c}{ Mortality $(\mathbf{9 5} \%$ CI) } \\
\cline { 2 - 3 } Time (d) & ECMO & CF-LVAD \\
\hline 200 & $25.2(20.3-30.3)$ & $12.6(8.9-16.3)$ \\
400 & $26.7(21.7-31.7)$ & $14.1(10.1-18.1)$ \\
600 & $26.7(21.7-31.7)$ & $15.9(11.6-20.2)$ \\
800 & $28.6(23.4-33.8)$ & $17.8(13.2-22.4)$ \\
1000 & $30.7(25.2-36.2)$ & $17.8(13.2-22.4)$ \\
\hline
\end{tabular}

$C I$, Confidence interval; $E C M O$, extracorporeal membrane oxygenation; $C F-L V A D$, continuous-flow left ventricular assist device.
TABLE E3. Corresponding $95 \%$ confidence interval (CI) in each time point for Kaplan-Meier curve (Figure 2)

\begin{tabular}{lccc}
\hline & \multicolumn{3}{c}{ Mortality $(\mathbf{9 5} \% \mathbf{C I})$} \\
\cline { 2 - 4 } Time (d) & Low & $\begin{array}{c}\text { Intermediate } \\
\text { MELD-XI }\end{array}$ & $\begin{array}{c}\text { High } \\
\text { MELD-XI }\end{array}$ \\
\hline 200 & $15.0(8.8-21.2)$ & $24.5(17.0-32.0)$ & $45.6(36.8-54.4)$ \\
400 & $18.4(11.6-25.2)$ & $24.5(17.0-32.0)$ & $45.6(36.8-54.4)$ \\
600 & $22.4(14.8-30.0)$ & $24.5(17.0-32.0)$ & $45.6(36.8-54.4)$ \\
800 & $26.5(18.3-34.7)$ & $24.5(17.0-32.0)$ & $51.0(41.6-60.4)$ \\
1000 & $26.5(18.3-34.7)$ & $24.5(17.0-32.0)$ & $51.0(41.6-60.4)$ \\
\hline
\end{tabular}

$\overline{C I}$, Confidence interval; $M E L D-X I$, model for end-stage liver disease excluding international normalized ratio.

TABLE E4. Corresponding $95 \%$ confidence interval (CI) in each time point for Kaplan-Meier curve (Figure E1)

\begin{tabular}{lcc}
\hline & \multicolumn{2}{c}{ Mortality $(\mathbf{9 5} \%$ CI) } \\
\cline { 2 - 3 } Time (d) & ECMO & CF-LVAD \\
\hline 200 & 0 & $2.0(1.8-2.2)$ \\
400 & $1.6(0-3.2)$ & $4.6(4.3-4.9)$ \\
600 & $1.6(0-3.2)$ & $6.8(6.2-7.2)$ \\
800 & $5.6(2.4-8.8)$ & $8.6(8.2-9.0)$ \\
1000 & $7.8(4.0-11.6)$ & $9.6(9.1-10.1)$ \\
\hline$C I$, Confidence interval; $E C M O$, extracorporeal membrane oxygenation; $C F-L V A D$, \\
continuous-flow left ventricular assist device.
\end{tabular}


TABLE E5. Corresponding $95 \%$ confidence interval (CI) in each time point for Kaplan-Meier curve (Figure E2)

\begin{tabular}{llr}
\hline \multirow{2}{*}{ Time (d) } & \multicolumn{2}{c}{ Mortality $(\mathbf{9 5} \%$ CI) } \\
\cline { 2 - 3 } & \multicolumn{1}{c}{ ECMO } & CF-LVAD \\
\hline 200 & $27.9(23.1-32.7)$ & $14.1(10.5-17.7)$ \\
400 & $29.2(24.3-34.1)$ & $16.6(12.7-20.5)$ \\
600 & $31.0(26.0-36.0)$ & $19.4(15.1-23.7)$ \\
800 & $32.8(27.6-38.0)$ & $20.8(16.4-25.2)$ \\
1000 & $34.7(29.3-40.1)$ & $22.4(17.8-27.0)$ \\
\hline$C I$, Confidence interval; $E C M O$, extracorporeal membrane oxygenation; $C F-L V A D$, \\
continuous-flow left ventricular assist device.
\end{tabular}

TABLE E6. Corresponding 95\% confidence interval (CI) in each time point for Kaplan-Meier curve (Figure E3)

\begin{tabular}{lccc}
\hline & \multicolumn{1}{c}{ Mortality (95\% CI) } & High MELD-XI \\
\cline { 2 - 4 } Time (d) & Low MELD-XI & Intermediate MELD-XI & $18.2(16.8-19.6)$ \\
\hline 200 & $5.9(5.5-6.3)$ & $10.4(9.6-11.2)$ & $21.1(19.6-22.6)$ \\
400 & $8.1(7.4-8.6)$ & $13.1(12.2-14.0)$ & $22.3(20.8-23.8)$ \\
600 & $10.2(9.7-10.7)$ & $15.4(14.5-16.3)$ & $23.5(21.9-25.1)$ \\
800 & $12.1(11.5-12.7)$ & $16.7(15.7-17.7)$ & $25.6(23.9-27.3)$ \\
1000 & $14.0(13.3-14.7)$ & $18.5(17.4-19.6)$ & \\
\hline
\end{tabular}

$C I$, Confidence interval; $M E L D$-XI, model for end-stage liver disease excluding international normalized ratio. 
TABLE E7. List of propensity-score matching covariates with frequency of missing data before multiple imputation

\begin{tabular}{lcc}
\hline \multicolumn{1}{c}{ Covariate } & $\begin{array}{c}\text { No. of } \\
\text { patients }\end{array}$ & $\begin{array}{c}\text { Percentage } \\
\text { missing }\end{array}$ \\
\hline Pulmonary vascular resistance & 928 & 14.8 \\
\hline College or higher education level & 537 & 8.9 \\
\hline Functional status & 279 & 4.5 \\
\hline Transfusion & 262 & 4.2 \\
\hline Antibiotics before transplant & 182 & 2.9 \\
\hline Chronic steroid use & 114 & 1.8 \\
\hline Ischemic time & 84 & 1.3 \\
\hline History of smoking & 52 & 0.8 \\
\hline MELD-XI score & 48 & 0.8 \\
\hline Dialysis & 37 & 0.6 \\
Diabetes & 15 & 0.2 \\
\hline Donor LVEF & 13 & 0.2 \\
\hline Donor cocaine use & 3 & 0.1 \\
\hline Donor episode of cardiac arrest & 3 & 0.1 \\
\hline Donor-recipient weight ratio & 0 & 0 \\
\hline Age & 0 & 0 \\
\hline Donor age & 0 & 0 \\
\hline Black & 0 & 0 \\
\hline Gender mismatch & 0 & 0 \\
\hline Expanded-criteria donor & 0 & 0 \\
\hline Status 1A & 0 & 0 \\
\hline Mechanical ventilation & 0 & 0 \\
\hline Inotropes & 0 & 0 \\
\hline IABP & 0 & 0 \\
\hline Ischemic etiology & 0 & 0 \\
\hline Distance from hospital to transplant center & 0 & 0 \\
\hline & & 0 \\
\hline
\end{tabular}

$M E L D-X I$, Model for end-stage liver disease excluding international normalized ratio; $L V E F$, left ventricular ejection fraction; $I A B P$, intra-aortic balloon pump.
TABLE E8. List of variables with frequency of missing data included in the multiple imputation before the multivariable logistic and Cox regression analyses among the 107 patients with extracorporeal membrane oxygenation

\begin{tabular}{lcc}
\hline \multicolumn{1}{c}{ Risk factor } & No. of patients & Percentage missing \\
\hline $\begin{array}{l}\text { Pulmonary vascular } \\
\text { resistance }\end{array}$ & 43 & 40.2 \\
PRA class 2 & 29 & 27.1 \\
\hline PRA class 1 & 27 & 25.2 \\
\hline Functional status & 13 & 12.1 \\
\hline Antibiotics before transplant & 6 & 5.6 \\
\hline MELD-XI & 5 & 4.7 \\
\hline Recipient A1 antigen & 5 & 4.7 \\
Recipient A2 antigen & 5 & 4.7 \\
\hline Recipient B1 antigen & 5 & 4.7 \\
\hline Recipient B2 antigen & 5 & 4.7 \\
Recipient DR1 antigen & 5 & 4.7 \\
\hline Recipient DR2 antigen & 5 & 4.7 \\
\hline A locus mismatch level & 5 & 4.7 \\
B locus mismatch level & 5 & 4.7 \\
\hline DR locus mismatch level & 5 & 4.7 \\
\hline HLA mismatch & 5 & 4.7 \\
\hline Transfusion since listing & 5 & 4.7 \\
\hline Ischemic time & 5 & 4.7 \\
\hline Dialysis & 3 & 2.8 \\
\hline$P R A$ Pane & 5 & \\
\hline
\end{tabular}

$P R A$, Panel reactive antibody; $M E L D-X I$, model for end-stage liver disease excluding international normalized ratio; $D R$, donor-recipient; $H L A$, human leukocyte antigen. 
TABLE E9. List of variables entered into the logistic and Cox regression analyses

\begin{tabular}{|c|c|c|c|}
\hline Variable & $P$ value* & Variable & $P$ value* \\
\hline \multicolumn{4}{|l|}{ Recipient factors } \\
\hline Mechanical ventilation & .53 & Body mass index & .89 \\
\hline Gender & .92 & Age & .76 \\
\hline MELD-XI & .47 & IABP & .75 \\
\hline ABO blood type & .49 & Diabetes & .35 \\
\hline History of smoking & .64 & Dialysis & .61 \\
\hline Functional status & .43 & Heart failure etiology (ischemic, dilated, congenital, others) & .62 \\
\hline Cerebrovascular accident & .54 & Cytomegalovirus IgM & .65 \\
\hline Cytomegalovirus IgG & .37 & Hepatitis B virus core & .31 \\
\hline Hepatitis B virus surface antigen & .29 & Hepatitis $C$ virus serostatus & .35 \\
\hline $\mathrm{RH}$ cross-matching at transplant center & .46 & Cardiac surgery since listing & .40 \\
\hline History of malignancy & .50 & Chronic steroid use & .40 \\
\hline Transfusion since listing & .65 & Black race & .42 \\
\hline Implantable cardioverter defibrillator & .67 & Antibiotics before transplant & .44 \\
\hline HLA mismatch level & .45 & DR locus mismatch level & .39 \\
\hline B locus mismatch level & .54 & A locus mismatch level & .48 \\
\hline PRA class I & .46 & DR2 antigen & .67 \\
\hline PRA class II & .47 & DR1 antigen & .56 \\
\hline B1 antigen & .89 & B2 antigen & .76 \\
\hline A1 antigen & .55 & A2 antigen & .51 \\
\hline Epstein-Barr virus serostatus & .87 & A1 antigen & .89 \\
\hline Pulmonary arterial pressure (systolic, diastolic, mean) & .45 & Pulmonary artery wedge pressure & .51 \\
\hline Status $1 \mathrm{~A}$ & .65 & Inotropes & .34 \\
\hline \multicolumn{4}{|l|}{ Donor factors } \\
\hline Ischemic time & .98 & Distance from transplant center & .17 \\
\hline Left ventricular ejection fraction & .38 & Vasodilators & .29 \\
\hline Pulmonary infection & .97 & Urinary tract infection & .88 \\
\hline Transfusion & .57 & Epstein-Barr virus IgM & .53 \\
\hline Episode of cardiac arrest & .49 & RPR-VDRL serology & .79 \\
\hline Tattoos & .61 & History of smoking & .67 \\
\hline Cocaine use & .64 & Creatinine & .76 \\
\hline Anticytomegalovirus serology & .74 & Heavy alcohol use & .86 \\
\hline Total bilirubin & .92 & Proteinuria & .44 \\
\hline Serum PH & .48 & History of hypertension & .47 \\
\hline DDAVP & .36 & Anticonvulsants & .77 \\
\hline Vasopressin & .55 & AST & .79 \\
\hline ALT & .58 & $\mathrm{~T} 3$ & .88 \\
\hline $\mathrm{T} 4$ & .45 & BUN & .54 \\
\hline Insulin & .66 & Heparin & .32 \\
\hline Age & .78 & Gender & .43 \\
\hline ABO type & .91 & $\geq 3$ inotropic agents & .63 \\
\hline Donor-recipient weight ratio & .79 & Racial mismatch & .54 \\
\hline Gender mismatch & .65 & Donor-recipient ABO match level & .77 \\
\hline Expanded criteria donor & .38 & Donor cause of death & .55 \\
\hline Antihypertensive agents & .78 & Hematocrit & .66 \\
\hline DR2 antigen & .82 & Diabetes & .68 \\
\hline A1 antigen & .84 & A2 antigen & .79 \\
\hline B1 antigen & .61 & B2 antigen & .57 \\
\hline DR1 antigen & .55 & DR2 antigen & .64 \\
\hline US citizenship & .55 & History of malignancy & .87 \\
\hline
\end{tabular}

MELD-XI, Model for end-stage liver disease excluding international normalized ratio; IABP, intra-aortic balloon pump; IgG, immunoglobulin G; IgM, immunoglobulin M; $H L A$, human leukocyte antigen; $D R$, donor-recipient; $P R A$, panel reactive antibody; $R P R-V D R L$, rapid plasma reagin-venereal disease research laboratory; $P H$, potential hydrogen; $D D A V P$, deamino-delta-d-arginine vasopressin; $A S T$, aspartate aminotransferase; $A L T$, alanine aminotransferase; $B U N$, blood urea nitrogen. $* P$ values were calculated to test for violation of proportionality using Cox proportional hazards model with time-dependent covariates during the follow-up period among the 107 patients with ECMO support. 
TABLE E10. Multivariable logistic regression for 90-day mortality and Cox regression for 3-year mortality as double robust methods among 164 propensity-matched patients

\begin{tabular}{|c|c|c|c|c|}
\hline \multirow[b]{2}{*}{ Characteristic } & \multicolumn{2}{|c|}{ Logistic regression for $90-d$ mortality } & \multicolumn{2}{|l|}{ Cox regression for 3-y mortality } \\
\hline & Odds ratio $(95 \%$ confidence interval $)$ & $P$ value & $\overline{\text { Hazard ratio }(95 \% \text { confidence interval) }}$ & $P$ value \\
\hline ECMO bridge & $2.37(0.99-5.69)$ & .053 & $1.84(0.92-3.65)$ & .084 \\
\hline College or higher education degree & $1.25(0.54-2.87)$ & .60 & $1.13(0.58-2.20)$ & .72 \\
\hline Donor tattoos & $1.29(0.54-3.06)$ & .57 & $1.19(0.61-2.32)$ & .62 \\
\hline Donor episode of cardiac arrest & $0.56(0.07-4.73)$ & .59 & $0.33(0.05-2.71)$ & .37 \\
\hline Donor LVEF & $1.03(0.98-1.09)$ & .25 & $1.01(0.96-1.05)$ & .81 \\
\hline Age & $1.01(0.98-1.04)$ & .45 & $1.00(0.98-1.03)$ & .87 \\
\hline Diabetes & $0.39(0.10-1.47)$ & .16 & $0.72(0.31-2.20)$ & .59 \\
\hline
\end{tabular}

ECMO, Extracorporeal membrane oxygenation; $L V E F$, left ventricular ejection fraction.

TABLE E11. Comparison of covariate imbalance between extracorporeal membrane oxygenation (ECMO) and continuous-flow left ventricular assist device (CF-LVAD) groups in the propensity-score matched sample after excluding variables with missing data

\begin{tabular}{|c|c|c|c|}
\hline Covariate & $\operatorname{ECMO}(\mathbf{n}=93)$ & CF-LVAD $(n=93)$ & Absolute standardized difference of means \\
\hline Recipient age & $45.3 \pm 15.1$ & $47.9 \pm 15.3$ & 0.14 \\
\hline Donor age & $32.7 \pm 12.9$ & $33.5 \pm 12.8$ & 0.09 \\
\hline Status $1 \mathrm{~A}$ & 85 (91.4) & $87(93.5)$ & 0.08 \\
\hline Ischemic etiology & $28(30.1)$ & $34(36.6)$ & 0.14 \\
\hline Black race & $16(17.2)$ & $17(18.3)$ & 0.03 \\
\hline Mechanical ventilation & $29(31.2)$ & $25(26.9)$ & 0.09 \\
\hline Intra-aortic balloon pump & $20(21.5)$ & $19(20.4)$ & 0.03 \\
\hline Inotropes & $53(57.0)$ & $60(64.5)$ & 0.15 \\
\hline Female gender & $31(33.3)$ & $31(33.3)$ & 0.00 \\
\hline $\begin{array}{l}\text { Gender mismatch } \\
\text { Male donor to female recipient } \\
\text { Female donor to male recipient }\end{array}$ & $\begin{array}{l}17(18.3) \\
15(16.1)\end{array}$ & $\begin{array}{l}12(14.0) \\
16(17.2)\end{array}$ & 0.06 \\
\hline Donor-to-recipient weight ratio & $1.06 \pm 0.28$ & $1.06 \pm 0.26$ & 0.00 \\
\hline Expanded criteria donor & $2(2.2)$ & $4(4.3)$ & 0.10 \\
\hline Distance from donor hospital to transplant center & $214 \pm 205$ & $194 \pm 189$ & 0.10 \\
\hline
\end{tabular}

\footnotetext{
Values are presented as mean \pm standard deviation or $\mathrm{n}(\%) . E C M O$, Extracorporeal membrane oxygenation; $L V E F$, left ventricular ejection fraction.
} 